\title{
Asymmetric information, ownership and quality of care: an empirical analysis of nursing homes \\ Shin-Yi Chou*
}

Department of Humanities and Social Sciences, New Jersey Institute of Technology and National Bureau of Economic Research, University Heights, Newark, NJ 07102-1982, USA

Received 1 September 2001; received in revised form 1 October 2001; accepted 8 October 2001

\begin{abstract}
Theoretically, when asymmetric information exists, nonprofit organizations, due to the attenuation of the property right, provide better quality of service than do the for-profits. Despite extensive theoretical examination of the behavior of nonprofits, there has been very little empirical testing of the plausibility of these theories. This article addresses the effect of ownership type on the quality of service in the nursing home industry, an environment particularly conducive to identifying the existence of asymmetric information. The study shows that the differences between for-profit and nonprofit homes do become manifest when asymmetric information is present. () 2002 Elsevier Science B.V. All rights reserved.
\end{abstract}

JEL classification: I1; L3

Keywords: Nursing home; Quality of care; Asymmetric information; Duration model; Unmeasured heterogeneity

\section{Introduction}

Since the early 1970s, economists have developed a rich array of theories to explain the role and the behavior of nonprofit organizations. In the early models, the behavior of nonprofit firms was hypothesized as maximizing the quality or quantity of the service they produce (Newhouse, 1970). A different view, summarized by Hansmann (1980), is that the impact of the organizational form on the firm's performance depends on the interaction between institutional structures and output characteristics. When the output is difficult for the consumer to observe or when asymmetric information exists between the provider and the consumer, nonprofit organizations, due to the attenuation of the property right, provide a better quality of service than do the for-profits. This idea, termed the "contract failure

\footnotetext{
* Tel.: +1-973-642-4177.

E-mail address: chou@admin.njit.edu (S.-Y. Chou).
} 
theory", has been further explored either theoretically or empirically by, among others, Easley and O'Hara (1983), Weisbrod and Schlesinger (1985) and Hirth (1999).

Slightly different arguments, based on the following observations, can be found in Hart et al. (1997) and Glaeser and Shleifer (2001). In the real world, formulating a complete contract to clearly specify the duties of each party under all possible contingencies is almost impossible. Thus, given the inevitability of an incomplete contract, the for-profit firms are more likely to cut corners which can be detrimental to the quality of service but which are hard to monitor. The nonprofit nondistribution constraint softens this incentive, leading nonprofit firms to provide a better quality of service.

Despite extensive theoretical examination of the role and the behavior of nonprofit organizations, there has been very little empirical testing of the plausibility of these theories. Most empirical studies have only attempted to examine whether differences exist between organizations with different ownership forms. However, these studies offer limited empirical evidence on how the interaction between ownership forms and asymmetric information affects the performance of the organization.

In this article, I examine the effect of the interaction between the ownership type and asymmetric information on the differences between for-profit and nonprofit organizations in terms of quality of service. Using nursing home data, I examine these theoretical models by testing for differences between for-profit and nonprofit homes under conditions of the existence of asymmetric information. Nursing home residents are usually frail and disabled; therefore, family members serve as representatives to monitor or evaluate the quality of care. In this situation, I use "visit frequency" as an indicator whereby asymmetric information is defined as existing when nursing home residents have no spouse or no child visiting within a month after admission.

To evaluate the relative merits of for-profit and nonprofit nursing homes, quality of care is measured by mortality and several adverse health outcomes (decubitus ulcers, dehydration and urinary tract infection). ${ }^{1}$ These are the key indicators of quality of care listed in a major report by the Institute of Medicine (1986). If nonprofit homes provide a better quality of service than do the for-profits only when asymmetric information exists, then the empirical results will support the plausibility of the contract failure or incomplete contract theory.

As can be seen in detail in the sections that follow, this study shows that the effect of nonprofit versus for-profit status on the quality of care is larger when asymmetric information exists between nursing homes and residents. I found no significant differences between for-profit and nonprofit homes when the residents have family members to monitor the quality of care. These results imply that nonprofit homes are superior to for-profit homes when the service is not monitored. In other words, for-profit homes have more incentive to compromise on those aspects of quality of care which are hard to monitor. This study further suggests that the contract failure or incomplete contract theory, which incorporates output characteristics to examine the behavior of nonprofits, is plausible, at least for nursing home care.

This article is organized in the following manner. Section 2 outlines the extant theories on the economics of nonprofits. In Section 3, a description of the data set and sample used

\footnotetext{
${ }^{1}$ Discussions about the definitions of quality of care are widely covered in most of the literature on this topic. For example, see Institute of Medicine (1986).
} 
in this study is included. In Section 4, I describe the econometric strategy used, followed by a discussion of the definition and rationale for as well as the construction of the variables in Section 5. Section 6 shows the estimation results and Section 7 concludes this study.

\section{Theoretical issues and previous empirical studies}

\subsection{Conceptual framework}

Organizations with different ownership types may perform differently in many ways. In this study, I only focus on one aspect, comparing the quality of service.

Some nonprofit firms may exist because of altruistic motives. In economic jargon, their founders may have utility functions that depend on the happiness or satisfaction gained from their acts of charity or the good reputation and prestige that result from their philanthropic behaviors (Rose-Ackerman, 1996). Nonprofit organizations may provide better quality of service because their managerial objective is to maximize a utility function with different maximands, such as quality and quantity, subject to a break-even budget constraint which is assumed to be exogenous (Newhouse, 1970; Scanlon, 1980; Gertler, 1991).

In this article, instead of emphasizing altruistic motivations, I stress the unobserved characteristics of the output and view the nonprofit firm in terms of their response to asymmetric information. For some services, consumers may feel unable to or find it difficult to evaluate the quality or quantity of the services provided by the organizations serving them. Under these circumstances, for-profit organizations may have more incentive to engage in opportunistic behaviors and to maximize their profits. The nonprofit firm, in contrast, owing to the nondistribution constraint, has less incentive to take advantage of consumers and may provide better quality of service. Therefore, nonprofit organizations will arise when the ordinary contractual mechanisms do not provide adequate protection to consumers and the value of the protection under the nondistribution constraint outweighs the managerial inefficiency, such as capital immobility and poor incentives for cost minimization.

Hansmann (1980), whose views are largely shared in the literature (Easley and O'Hara, 1983; Weisbrod and Schlesinger, 1985; Hirth, 1999), uses "contract failure" to explain the superiority of nonprofit status when the output cannot be observed without incurring costs. Similarly, Arrow (1963) has suggested that the dominance of private nonprofit hospitals is, in part, because of lower transactions costs between the hospital and patients. In the hospital industry, patients will have greater difficulty judging the quality of care in advance because hospital care usually involves complex technology and complicated medical knowledge. Nonprofit organizations will arise to fill a market niche in situations in which consumers feel unable to effectively judge the quality of care they receive.

Similar arguments have been made by Hart et al. (1997) and Glaeser and Shleifer (2001), as well as in the literature on incomplete contract theory developed by Grossman and Hart (1986) and Hart and Moore (1990). These authors assume that there are so many possible contingencies ex ante that it is impossible to anticipate all of them when forming a contract. Ownership of assets confers control and bargaining power on the owner in situations in which a contract does not completely specify what is to be done. As a result, owners may have an incentive to reduce costs which can, in turn, be detrimental to non-contractible quality. 
Under incomplete contracts, for-profit firms are more likely to exploit non-contractible quality by cutting non-contractible costs to maximize returns (Glaeser and Shleifer, 2001). The nonprofit nondistribution constraint softens this incentive and assures higher quality of care.

The role and the behavior of nonprofit organizations have been extensively examined on a theoretical level. However, it is very difficult to empirically test these theoretically plausible models. Most empirical analyses have only detected and evaluated differences in the behavior of various organizational forms. However, these empirical studies have failed to further investigate if the differences are a function of contract failure or incomplete contract due to asymmetric information. This study, using nursing home data, is the first attempt to investigate these theoretical models empirically.

\subsection{Nursing home characteristics and previous studies}

According to the 1995 National Nursing Home Survey (NNHS), 66\% of the nursing homes were for-profit (Strahan, 1997). For the nursing home market, where for-profit and nonprofit homes coexist, an important research question that affects public policy emerges: how important is the role of asymmetric information in explaining the different behaviors of nonprofit and for-profit homes? If it is true that the nonprofit homes provide a better quality of service simply because of their altruistic motivations, then policy with regard to monitoring output or rewarding performance might be an effective mechanism to improve the quality of care. Nevertheless, if it is true that the nonprofits are superior to for-profits only when the output is difficult to observe, then governmental regulation of product quality may be a costly means of unreliable efficacy. To the extent that some aspect of quality is hard to monitor by the nursing home residents and their family members, it may also be difficult for the policy makers to observe.

In nursing home care, the patients are usually cognitively and/or physically disabled; therefore, they usually have difficulty in evaluating the quality of nursing home care before purchasing it. Even after entering the nursing home, the patients do not often press complaints about bad quality of care against managers or seek out an alternative institution. ${ }^{2}$ Furthermore, the primary financial source of nursing home care is from a third party, such as Medicaid. ${ }^{3}$ In such cases, only the third-party payer may have the necessary leverage to insist upon adequate performance. Family members of the nursing home residents may serve as representatives to evaluate the quality of care before purchasing it or to monitor the service by frequent visits after their parents or spouse enter the nursing home. ${ }^{4}$ Therefore,

\footnotetext{
${ }^{2}$ Dick et al. (1994) found that $35 \%$ of individuals who reach age 65 have at least one nursing home admission. Although a substantial minority $(10 \%)$ has more than one admission, very few have a large number of admissions; only $0.5 \%$ have more than four.

${ }^{3}$ Based on the 1995 National Nursing Home Survey, at the time of admission, nursing home residents relied primarily on Medicaid (38\%). The second most common primary source of payment at admission was private insurance or family support (32\%), followed by Medicare (25\%). However, the Survey also indicated that after being in the nursing home for a period of time, the number of residents relying on Medicaid increased considerably $(56 \%)$.

${ }^{4}$ Having no children increased the likelihood of nursing home entry (Hoerger et al., 1996) and having living children was associated with a higher probability of leaving a nursing home (Garber and MaCurdy, 1990).
} 
the potential for asymmetric information between the patients and nursing homes is likely to abate when the patients have family members.

Using different approaches and measures, some studies found that nonprofit homes are superior in quality to for-profit homes (e.g. Weisbrod and Schlesinger, 1985; Gertler, 1989; Zinn et al., 1993; Davis, 1993; Zinn, 1994), while others found mixed or insignificant evidence (e.g. Nyman, 1988; Cohen and Dubay, 1990). ${ }^{5}$ These studies can only answer the question: for any given nursing home, does type of ownership affect the nursing home's behavior in terms of quality of service? But are not able to address the further question: how does ownership status interrelate with output characteristics to affect the nursing home's behavior? This article is an attempt to do so and will address differences of response to asymmetric information between for-profit and nonprofit nursing homes.

\section{Data and sample selection}

The data used in this analysis are superior to those used in previous studies in three respects. First, I use not only nursing home characteristics (e.g. ownership), but also resident characteristics (e.g. demographic characteristics and health conditions). Second, detailed and longitudinal clinical data (such as diagnosis codes) have been used to identify bad health outcomes at a specific time. Third, the most important data characteristics for this article, marital status and child characteristics, were used to define the existence of asymmetric information.

All the individual characteristics data for this study come from the 1984, 1989, and 1994 National Long-Term Care Survey (NLTCS), in which the sample was drawn from Medicare beneficiary enrollment files. The NLTCS is a nationally-representative sample of the disabled elderly who are either community or institutional residents. All respondents in the NLTCS are at least 65 years old and need help in one or more activities of daily livings (ADLs), such as eating and bathing, or instrumental activities of daily livings (IADLs), such as shopping and doing the laundry.

In addition to demographic characteristics (such as age, gender, ethnicity, education, marital status and income information) and child characteristics, the NLTCS also includes extensive information about health and functional status (represented by limitations in ADLs), and cognitive functioning. The sample can be linked to the Medicare Parts A and B service records from 1982 to 1995, so that detailed medical records and types of service used can be tracked longitudinally. The provider numbers on the claim records in the skilled nursing facility are required to identify the nursing homes which, in turn, allow me to assign ownership codes and other nursing home characteristics from the Medicare Provider of Service (MPOS) file, 1991-1995. These data, gathered by the Health Care Financing Administration, include the provider number, county, state, and characteristics for each Medicare-approved provider. Date of death for all NLTCS respondents is verified using Medicare enrollment records, the National Death Index, and state vital records systems.

The NLTCS has been used by a number of researchers. However, these data have some deficiencies in determining nursing home utilization among the elderly. The institutional

\footnotetext{
${ }^{5}$ See Hawes and Phillips (1986) and Davis (1991) for reviews and references before 1990.
} 
questionnaire only contains nursing home admission dates, and data on the length of stay in the screener questionnaire are missing. To deal with these problems with the data, I combine NLTCS data with all the relevant information from Medicare claims data, such as place of service and discharge destination, to construct more accurate nursing home stays. ${ }^{6}$

The sample used to estimate the model consists of NLTCS participants who have been institutionalized or had a medical record in a nursing home at least once from 1984 to 1994. ${ }^{7}$ In order to obtain data on the nursing home characteristics, I merge the sample with the Medicare SNF records to obtain the provider numbers of the nursing homes. Only 3141 residents have Medicare claims records in a skilled nursing facility. If the residents do not have any medical service or treatment in the nursing home, I cannot find the provider numbers of the nursing homes they reside in. This selection process implies that the sample contains more frail and sicker residents. ${ }^{8}$ Using the provider numbers obtained from the Medicare SNF file, I am able to get nursing home characteristics from the MPOS. ${ }^{9}$ The case will be selected once the provider number can be merged with the MPOS from 1991 to 1995 , regardless of the different admission year. ${ }^{10}$ This selection process results in an analysis sample of 2992.

In order to control for health, financial and marital status before entering a nursing home, I use the information from NLTCS interviews prior to the nursing home admission date. Once a case is selected, it is followed through until the time of death or nursing home discharge, whichever occurred first. The sample selection process results in an analysis sample of 2992 elderly who were admitted to 1887 different nursing homes. In this sample, 1275 elderly patients did not have a spouse or any child visiting within the month following admission, and are defined as those who have asymmetric information about nursing home care. ${ }^{11}$ Of

\footnotetext{
${ }^{6}$ The person is assumed to be in the nursing home in the same month as the medical service occurred, if the place of physician service is in SNF or in nursing facility, or if the provider number of the medical records corresponds to SNF and nursing facility, or the discharged destination from home health, inpatient and outpatient is SNF or ICF.

${ }^{7}$ A total of 15,288 persons were institutionalized or had a medical record in any nursing home from 1984 to 1994, and 12,478 persons were identified based on the Medicare Claims Data (i.e. no records found from NLTCS), especially from the physician service file. According to a report by the Duke University Center for Demographic Studies, there were a total of 35,848 distinct individuals living in the community and in institutions over the 12 years spanned by the four surveys (1982, 1984, 1989 and 1994). I only study those who entered the nursing home after 1984. I drop 231 cases where the reported death date was prior to the nursing home admission date.

${ }^{8}$ Compared with the excluded cases, the analysis sample contains more female and residents who were older, with higher risk scores, lower income, more ADLs limitations and higher cognitive scores.

${ }^{9}$ One potential problem is that Medicare only covers a short nursing home stay, and Medicaid is the major financial source for long-term care. In this case, I may lose some observations by merging with the MPOS, but not the Medicaid Provider of Service. In order to receive Medicare and Medicaid patients and payments, nursing facilities must receive certification after meeting predetermined state qualifications. The 1995 National Nursing Home Survey (NNHS) found that nearly all nursing homes had some form of certification in 1995, and more than two-thirds of all homes were certified by both Medicare and Medicaid. According to these statistics, one should not expect to lose a lot of cases in the sample by merging with the MPOS.

${ }^{10}$ The most important information from MPOS for this study is the ownership codes; therefore, this selection process assumes that nursing homes did not convert to different ownership forms frequently from 1991 to 1995 . Only 149 cases are lost by merging with the MPOS.

11 "Living distance" and "visit frequency" are highly correlated (correlated coefficient is equal to 0.93 ) in this sample. Therefore, using either visit frequency or living distance to define the existence of asymmetric information yields similar results.
} 
these 1275 patients, 763 were admitted to for-profit homes, 432 to non-profit homes and 80 to government-owned homes. The other 1717 residents who had a spouse or at least one child visiting within 1 month are defined as those who do not have any asymmetric information about nursing home care. Of these 1717 patients, 1007 were admitted to for-profit homes, 612 to non-profit homes and 98 to government-owned homes.

\section{Econometric strategy}

The primary goal of the empirical analysis is to investigate the effect of ownership status on nursing home quality of care and the differences in this effect depending on the existence of asymmetric information. I employ a duration model to assess mortality rate and the risk of having other adverse health outcomes in the nursing homes. I also consider the potential unmeasured heterogeneity in the estimations.

The major advantage of hazard models versus discrete-time alternatives, such as logit and probit models or discrete-time Markov models, is that hazard models allow continuous-time analysis regardless of the periods used in the data themselves. Thus, probabilities can be predicted over a period of 1 year when the data refer to 2-year intervals. In addition, the hazard model can be used to account for unmeasured heterogeneity. The major advantage of hazard models versus regression techniques is the ease with which incomplete spells are accommodated.

The hazard is parameterized using a proportional hazard form

$$
h(t)=h_{0}(t) e^{X^{\prime} \beta},
$$

where $h_{0}(t)$ is the baseline hazard at time $t, X$ a vector of explanatory variables which are assumed to be time invariant, and $\beta$ a vector of parameters to be estimated. The Weibull baseline hazard $h_{0}(t)=\alpha t^{\alpha-1}$ is used.

Residents' tastes and some other unmeasured health conditions are unobservable to an econometrician. If unobserved heterogeneity is present, the conditional hazard is written as

$$
h(t \mid v)=v h_{0}(t) e^{X^{\prime} \beta}
$$

where $v$ is a random variable that is assumed to be independent of $X$. In order to obtain consistent estimates of parameters of the conditional hazard, $v$ should be integrated out over its distribution $g(v)$.

Suppose $\delta_{i}$ is the indicator showing that the individual $i$ survives at time $t$, and for someone censored we only know that $T_{i} \geq t$ and $\delta=0$. Thus, the likelihood contribution from a single individual who is observed having a failure time $t$ is

$$
f(t)=\int_{-\infty}^{\infty}\left\{h(t \mid v) \exp \left(-\int_{0}^{t} h(u \mid v) \mathrm{d} u\right)\right\} g(v) \mathrm{d} v
$$

and the probability of surviving at least to $t$ is

$$
S(t)=1-F(t)=\int_{-\infty}^{\infty} \exp \left(-\int_{0}^{t} h(u \mid v) \mathrm{d} u\right) g(v) \mathrm{d} v .
$$


The likelihood function for a sample of $N$ individuals can be written as

$$
L=\prod_{i=1}^{N}[f(t)]^{\delta_{i}}[1-F(t)]^{1-\delta_{i}}
$$

Unmeasured terms can be eliminated by integration, which implies an assumption of the functional form for the distribution of unobserved terms. Heckman and Singer (1984) claim that the distribution assumption of unmeasured heterogeneity usually results in very different estimates of the hazard function and propose using the nonparametric method to incorporate random effects. In this paper, I adopt the method used in Butler et al. (1989), which originates from Heckman and Singer (1984), to estimate the semiparametric duration model. The distribution of unobserved heterogeneity can be approximated by a step function. The strategy can be represented as follows:

$$
S(t)=\int_{-\infty}^{\infty} \exp \left(-v e^{X^{\prime} \beta} t^{\alpha}\right) g(v) \mathrm{d} v \approx \sum_{i=1}^{\mathrm{NHP}} \exp \left(-u_{i} e^{X^{\prime} \beta} t^{\alpha}\right) w_{i},
$$

where

$$
\sum_{i=1}^{\mathrm{NHP}} w_{i}=1, \quad 0 \leq w_{i} \leq 1, \quad i=1, \ldots, \mathrm{NHP}
$$

and NHP is number of semiparametric points. The number of integration points $\left(u_{i}\right)$ is fixed in advance, and only weights $\left(w_{i}\right)$ are estimated.

In the absence of unmeasured heterogeneity, NHP $=1$ and $w_{1}=1$. Therefore, rejecting a restriction to one point using the likelihood ratio test is evidence for the presence of unmeasured heterogeneity.

The primary interest lies not in the parameters $\beta$ and $\alpha$, but in the effects of the covariates $X$ on the expected duration. The expected duration is defined as

$$
E(t)=\int_{0}^{\infty} t f(t) \mathrm{d} t=\int_{0}^{\infty} S(t) \mathrm{d} t .
$$

If the covariate is a dummy variable $d$, the marginal effect should be computed as $E(d=1)-E(d=0)$. The probability of succumbing between $t$, and $t_{\mathrm{e}}$ can be expressed as

$$
P_{t_{\mathrm{s}}}^{t_{\mathrm{e}}}=F\left(t_{\mathrm{e}}\right)-F\left(t_{\mathrm{s}}\right)
$$

Similarly, the marginal effect of a dummy variable can be expressed as $P_{t_{\mathrm{s}}}^{t_{\mathrm{e}}}(d=1)-P_{t_{\mathrm{s}}}^{t_{\mathrm{e}}}$ $(d=0)$.

\section{Empirical specification}

\subsection{Dependent variables}

In order to examine the relationship between nursing home care and resident health outcomes using the duration model, dependent variables are specified to include duration time 
Table 1

Summary statistics for dependent variables ${ }^{\mathrm{a}}$

\begin{tabular}{|c|c|c|c|c|}
\hline & Death & Decubitus ulcers & Dehydration & Urinary tract infections \\
\hline & \multicolumn{4}{|c|}{$\begin{array}{l}\text { With asymmetric information (no spouse and no child visiting } \\
\text { within } 1 \text { month after admission) }\end{array}$} \\
\hline All spells (months) & $38.46(31.24)$ & $37.40(30.83)$ & $35.97(30.31)$ & 33.45 (28.79) \\
\hline Complete spells (months) & $32.74(27.45)$ & $33.49(26.43)$ & $35.59(25.70)$ & $37.20(26.17)$ \\
\hline Number of complete spells & 470 & 111 & 204 & 308 \\
\hline Number of censored spells & 805 & 1164 & 1071 & 967 \\
\hline \multirow[t]{2}{*}{ Sample size } & 1275 & & & \\
\hline & \multicolumn{4}{|c|}{$\begin{array}{l}\text { With asymmetric information (has spouse or at least one child } \\
\text { visiting within } 1 \text { month after admission) }\end{array}$} \\
\hline All spells (months) & $35.00(30.12)$ & $34.00(29.79)$ & $32.73(29.14)$ & $29.86(27.67)$ \\
\hline Complete spells (months) & $30.88(27.01)$ & $33.09(24.40)$ & $32.51(23.44)$ & $31.49(23.43)$ \\
\hline Number of complete spells & 580 & 158 & 254 & 441 \\
\hline Number of censored spells & 1137 & 1559 & 1463 & 1276 \\
\hline Sample size & 1717 & & & \\
\hline
\end{tabular}

${ }^{\text {a }}$ S.D. are in parentheses.

from admission until death and time from admission until bad health outcomes (decubitus ulcers, dehydration and urinary tract infections). To identify adverse health outcomes, I use all the diagnosis codes in Medicare claims data (Inpatient, Outpatient, SNF, Home Health, Hospice and Physician Part B) of decubitus ulcers, urinary tract infections and dehydration. ${ }^{12}$

The first occurrence of the condition after being admitted to a nursing home is used to construct the dependent variable. I ignore the possibilities of re-occurrence (multiple spells) in this analysis, and follow the death and adverse health outcomes for 1 month after discharge. More precisely, the dependent variable $T$ in the duration model can be defined as

$$
\min \left\{t_{\mathrm{s}}-t_{\mathrm{n}}, t_{\mathrm{d}}-t_{\mathrm{n}}, t_{1}-t_{\mathrm{n}}\right\},
$$

where $t_{\mathrm{S}}$ is the date of having an adverse health outcome, $t_{\mathrm{n}}$ the date of nursing home admission, $t_{\mathrm{d}}$ the date of death and $t_{1}$ the date of 1 month after discharge. ${ }^{13}$ The date of death and the date of 1 month after discharge, whichever occurs first, will be the censored date, if an adverse health outcome is not observed.

The means and standard deviations of the dependent variables are given in Table 1. Out of the sample of 1275 residents who did not have any family member visiting within 1 month after admission, $36.86 \%$ died in nursing homes or within a month after discharge

\footnotetext{
${ }^{12}$ International classification of diseases (ICD-9-CM) codes used to select cases are as follows. Decubitus ulcers: 707.0 and 785.4. Dehydration: 276.5, 276.0, 276.1 and 276.8. Urinary tract infections: 593.89, 597.80, 599.90, 595, 595.0-595.9, 597, 597.0, 597.8, 597.80, 597.81, and 597.89.

${ }^{13}$ Previous studies used survey date as the censored date when examining the mortality in nursing home. However, residents might be discharged much earlier than the survey date. In this study, I used 1 month after discharge as the censored date if death was not observed. Results on bad health outcomes are similar no matter whether the censored date is discharge date or the date of one month after discharge.
} 
and the average survival time was 38.46 months, and this mean included 470 right censored spells. The death rate was $33.78 \%$ and the average survival time was 35.00 months for the sample with a family member visiting within 1 month after discharge. For other adverse health outcomes, for example, $16 \%$ of the sample without a family member visiting within 1 month after admission and $14.79 \%$ of the sample with a family member visiting within 1 month after admission had dehydration.

\subsection{Explanatory variables}

Explanatory variables can be roughly grouped into three categories: nursing home characteristics, personal characteristics and health before entering a nursing home. Table 2 summarizes the sample's statistics of these variables.

\subsubsection{Nursing home characteristics}

I categorize ownership into three types: nonprofit, government-owned, and for-profit which is the omitted reference group. In the sample with no spouse and no child visiting within a month after admission, 59.8\% were in for-profit homes, 33.9\% in nonprofit homes, and $6.3 \%$ in government-owned homes. The differences in the proportion of the nonprofit home residents who have and do not have asymmetric information are small in magnitude and statistically insignificant, regardless of whether the definition of asymmetric information is based on living distance or visit frequency. This result suggests that the potential for sample selection may not cause serious biases in this study, since the

Table 2

Sample statistics

\begin{tabular}{|c|c|c|c|c|}
\hline & \multicolumn{2}{|c|}{$\begin{array}{l}\text { With asymmetric information } \\
\text { (no spouse and no child visiting } \\
\text { within } 1 \text { month after admission) }\end{array}$} & \multicolumn{2}{|c|}{$\begin{array}{l}\text { Without asymmetric information } \\
\text { (has spouse or at least one child } \\
\text { visiting within } 1 \text { month after } \\
\text { admission) }\end{array}$} \\
\hline & Mean & S.D. & Mean & S.D. \\
\hline \multicolumn{5}{|l|}{ Nursing home ownership } \\
\hline Nonprofit & 0.339 & 0.473 & 0.356 & 0.479 \\
\hline Government-owned & 0.063 & 0.243 & 0.057 & 0.232 \\
\hline \multicolumn{5}{|l|}{ Personal characteristics } \\
\hline Male & 0.187 & 0.390 & 0.397 & 0.489 \\
\hline Age (at nursing home admission) & 80.803 & 6.881 & 79.715 & 7.390 \\
\hline White & 0.888 & 0.316 & 0.907 & 0.291 \\
\hline Education (years) & 10.013 & 2.326 & 9.586 & 3.022 \\
\hline Income (in 1994 US\$, ‘000) & 13.916 & 6.704 & 15.811 & 9.601 \\
\hline Married & & & 0.644 & 0.479 \\
\hline Health before entering nursing homes & 0.706 & 1.551 & 0.938 & 1.643 \\
\hline No. of ADLs & 1.782 & 3.472 & 3.108 & 4.168 \\
\hline Cognition score & 0.230 & 0.915 & 0.290 & 1.022 \\
\hline Risk score & 0.339 & 0.473 & 0.356 & 0.479 \\
\hline Sample size & 1275 & & 1717 & \\
\hline
\end{tabular}


patients who have asymmetric information do not disproportionately reside in nonprofit homes. ${ }^{14}$

\subsubsection{Personal characteristics}

Demographic variables are gender, race, years of education, and marital status at the time of the NLTCS interview before nursing home admission. Compared to the nursing home residents with family support, those without family support were female, older, more educated and had lower family income, regardless of whether the definition of family support is based on living distance or visit frequency. In the sample without spouse and even one child visiting within 1 month after admission, $18.7 \%$ were male and $88.8 \%$ were white. Age at the date of nursing home admission is treated as a time-invariant variable in the duration model. The average age at the date of nursing home admission was 81 for the sample with asymmetric information. I also include total household income at the time of the NLTCS interview before nursing home admission. Income is deflated to 1994 dollars using the all-items Consumer Price Index, and the average income was US\$ 13,916 for those who did not have spouse and at least one child visiting within 1 month after admission.

\subsubsection{Health status before entering nursing home}

Health status is indicated by the number of ADLs, cognitive status and risk scores. The ADLs, based on questions about problems with getting out of bed, bathing, dressing, eating, using the toilet and walking, range from 0 to 6 . Cognition scores, based on 10 common sense questions, including "who is the current president", "what city do you live in", range from 0 to 10. A higher score on the cognition test indicates better functioning. The risk score (DxCG index) is used by Medicare and others to forecast future payments on behalf of the individual (DxCG, 1996; Ellis et al., 1996). The risk score is created based on patients' age, sex and diagnoses codes in all hospital claims record using ICD-9-CM codes before entering nursing homes. Nursing home residents who had asymmetric information had fewer ADL limitations, were more cognitively unaware and had lower risk scores than those who did not.

\subsection{Empirical specification}

To examine how ownership status under asymmetric information affects the quality of care, $X^{\prime} \beta$ in Eq. (1) is specified as

$$
X^{\prime} \beta=\alpha+\beta_{0} G+\beta_{1} \mathrm{NP}+\beta_{2} \mathrm{AINF}+\beta_{3} G \times \mathrm{AINF}+\beta_{4} \mathrm{NP} \times \mathrm{AINF}+\gamma Z+\tau T .
$$

The descriptions of the variables in Eq. (9) are as follows: $G$ and NP are indicators of government-owned and nonprofit nursing homes, respectively, AINF the indicator of the

\footnotetext{
${ }^{14}$ Previous studies have argued that nonprofit status will serve as a signal of better quality of service when asymmetric information exists (Hansmann, 1980; Weisbrod and Schlesinger, 1985; Easley and O'Hara, 1983; Hirth, 1999). Therefore, consumers who have difficulty monitoring the quality of service will prefer to choose nonprofit organizations to avoid losses from informational handicaps. If it is true that nonprofit homes disproportionately attract those who are frail and incapable of monitoring quality of care (Spector et al., 1998), this selection bias will work against the result that nonprofit homes provide better quality of service.
} 
existence of asymmetric information, $Z$ a vector of other explanatory variables described in the previous section, and $T$ includes a series of year dummies. Thus, $\beta_{0}$ and $\beta_{1}$ capture the effects of ownership status, regardless of the existence of asymmetric information, and $\beta_{2}$ reflects the effects of asymmetric information for all nursing homes.

With asymmetric information, the difference between nonprofits and for-profits is captured by $\left(\beta_{1}+\beta_{4}\right)$. Without asymmetric information, the difference is captured by $\beta_{1}$. Negative coefficients of $\beta_{1}$ and $\beta_{4}$ suggest that nonprofit homes provide a better quality of service than for-profit homes. Thus, $\beta_{4}$ is a "difference-in-differences" estimator which measures the differences between nonprofit and for-profit homes with and without asymmetric information. If $\beta_{4}$ is negative and statistically significant, and $\beta_{1}$ is not statistically significant, the empirical findings will support the theoretical argument that the nonprofit homes provide better quality of service only when asymmetric information exists.

\section{Empirical results}

To control for the potential unobserved heterogeneity, I estimate the model with two mass points. Likelihood ratio tests reject the null hypothesis that the unobserved heterogeneity is absent for mortality $\left(\chi_{(1)}^{2}=140\right)$, decubitus ulcers $\left(\chi_{(1)}^{2}=7.78\right)$ and dehydration $\left(\chi_{(1)}^{2}=22.54\right)$, but not for urinary tract infections $\left(\chi_{(1)}^{2}=3.20\right)$ (first panel of Table 3 ). Therefore, for mortality, decubitus ulcers and dehydration, I report results when the unobserved heterogeneity is controlled; for urinary tract infections, I report results without controlling the unobserved heterogeneity.

There are no significant differences between nonprofit and for-profit homes when asymmetric information is absent ( $\beta_{1}$ is not statistically significant for all quality indicators). This result is important and suggests that the difference between nonprofit and for-profit homes without asymmetric information can serve as a good benchmark to purge the true difference with asymmetric information. Ranked in terms of mortality and other adverse health outcomes, nonprofit homes were superior when the residents had asymmetric information (first panel of Table 3). Nonprofit home residents had lower mortality rates and were less likely to have decubitus ulcers, dehydration and urinary tract infections when the residents had no spouse or child visit within the first month. The estimated coefficient of $\beta_{4}$ $(\mathrm{NP} \times \mathrm{AINF})$ on mortality is statistically significant at the $10 \%$ level, and the coefficients on dehydration and urinary tract infections are statistically significant at the 5\% level. These results suggest that the "difference-in-differences" is statistically significant in terms of the occurrence of bad health outcomes.

Since residents could monitor the quality of service as well, I conduct another experiment by adding a second criterion: "residents are cognitively unaware," to determine the existence of asymmetric information. ${ }^{15}$ In the second panel of Table 3, the estimated coefficient $\beta_{4}$ becomes larger in value for both dehydration and urinary tract infections and is more significant for the latter. These results further support previous results that the differences between nonprofit and for-profit homes are bigger when asymmetric information exists.

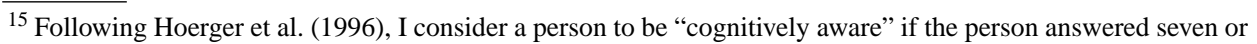
more questions correctly.
} 
Table 3

Effects of nonprofit status on nursing home quality of care ${ }^{a}$

\begin{tabular}{|c|c|c|c|c|}
\hline & Death & Decubitus ulcers & Dehydration & Urinary tract infections \\
\hline & \multicolumn{4}{|c|}{ (1) Asymmetric information (no spouse and no child visiting within 1 month after admission) } \\
\hline Nonprofit status $\left(\beta_{1}\right)$ & $-0.098(0.105)$ & $0.117(0.186)$ & $-0.088(0.146)$ & $-0.019(0.105)$ \\
\hline Nonprofit status $\times$ asymmetric information $\left(\beta_{4}\right)$ & $-0.261^{\mathrm{b}}(0.159)$ & $-0.442(0.304)$ & $-0.504^{\mathrm{c}}(0.233)$ & $-0.434^{\mathrm{c}}(0.713)$ \\
\hline \multicolumn{5}{|l|}{ Likelihood ratio test of unmeasured heterogeneity } \\
\hline Statistic & 140.008 & 7.778 & 22.536 & 3.196 \\
\hline Reject a restriction to one point? & Yes & Yes & Yes & No \\
\hline Nonprofit status $\left(\beta_{1}\right)$ & $-0.182^{b}(0.098)$ & $0.081(0.176)$ & $-0.098(0.137)$ & $-0.019(0.099)$ \\
\hline Nonprofit status $\times$ asymmetric information $\left(\beta_{4}\right)$ & $-0.081(0.162)$ & $-0.436(0.322)$ & $-0.619^{\mathrm{c}}(0.252)$ & $-0.567^{\mathrm{d}}(0.186)$ \\
\hline \multicolumn{5}{|l|}{ Likelihood ratio test of unmeasured heterogeneity } \\
\hline Statistic & 139.836 & 8.010 & 22.892 & 3.454 \\
\hline Reject a restriction to one point? & Yes & Yes & Yes & No \\
\hline
\end{tabular}

${ }^{\text {a }}$ S.E. are in parentheses.

${ }^{\mathrm{b}}$ Statistically significant at the $10 \%$ level.

${ }^{\mathrm{c}}$ Statistically significant at the $5 \%$ level.

d Statistically significant at the $1 \%$ level. 
Table 4

Difference-in-differences estimates on expected duration and probability of having bad health outcomes within 1 and 2 years $^{\mathrm{a}}$

\begin{tabular}{|c|c|c|}
\hline & $\begin{array}{l}\text { (2) Asymmetric } \\
\text { information (no spouse } \\
\text { and no child visiting } \\
\text { within } 1 \text { month after } \\
\text { admission) }\end{array}$ & $\begin{array}{l}\text { Specification (1) } \\
+ \text { residents are } \\
\text { cognitively } \\
\text { unaware }\end{array}$ \\
\hline \multicolumn{3}{|l|}{ Death } \\
\hline Expected duration & $3.401(2.354)$ & $0.998(2.072)$ \\
\hline 1-year mortality & $-0.093^{\mathrm{b}}(0.056)$ & $-0.029(0.059)$ \\
\hline 2-year mortality & $-0.081(0.054)$ & $-0.024(0.050)$ \\
\hline \multicolumn{3}{|l|}{ Decubitus ulcers } \\
\hline Expected duration & $10.234(6.891)$ & $10.097(7.277)$ \\
\hline Probability of having decubitus ulcers within 1 year & $-0.081(0.060)$ & $-0.079(0.060)$ \\
\hline Probability of having decubitus ulcers within 2 years & $-0.131(0.092)$ & $-0.128(0.094)$ \\
\hline \multicolumn{3}{|l|}{ Dehydration } \\
\hline Expected duration & $10.447(5.548)$ & $13.009^{\mathrm{c}}(6.044)$ \\
\hline Probability of having dehydration within 1 year & $-0.104^{\mathrm{c}}(0.052)$ & $-0.122^{\mathrm{c}}(0.055)$ \\
\hline Probability of having dehydration within 2 years & $-0.170^{\mathrm{c}}(0.077)$ & $-0.203^{\mathrm{c}}(0.080)$ \\
\hline \multicolumn{3}{|l|}{ Urinary tract infections } \\
\hline Expected Duration & $9.677(3.735)$ & $12.442^{\mathrm{d}}(3.989)$ \\
\hline Probability of having urinary tract infections within 1 year & $-0.054^{\mathrm{b}}(0.028)$ & $-0.067^{\mathrm{c}}(0.032)$ \\
\hline Probability of having urinary tract infections within 2 years & $-0.103^{\mathrm{c}}(0.051)$ & $-0.129^{c}(0.058)$ \\
\hline
\end{tabular}

a S.E. are in parentheses.

${ }^{\mathrm{b}}$ Statistically significant at the $10 \%$ level.

${ }^{\mathrm{c}}$ Statistically significant at the $5 \%$ level.

${ }^{\mathrm{d}}$ Statistically significant at the $1 \%$ level.

In Table 4, I present the difference-in-differences estimates of the effects of nonprofit status on the expected duration of stay in the nursing home until death and until other adverse health outcomes, when other variables are held at their mean values. I also report the difference-in-differences estimates of the effects of nonprofit status on the predicted 1-and 2-year mortality rates and on the predicted probability of having adverse health outcomes within 1 and 2 years. When the asymmetric information is defined based on visit frequency, the gap of the expected duration of stay in the home until death between nonprofit and for-profit homes is 3.40 months higher with asymmetric information than without. The differences of 1-year mortality and 2-year mortality between nonprofit and for-profit are 9.3\% and $8.1 \%$ lower with asymmetric information than without. In terms of mortality, the differences between nonprofit and for-profit homes with and without asymmetric information are not statistically significant (except for 1-year mortality, which is significant at the $10 \%$ level). Predicted probabilities of having dehydration and urinary tract infections are lower in nonprofit homes when asymmetric information exists, and the results are statistically significant at the $5 \%$ level.

When adding residents' cognitive status to determine the existence of asymmetric information, the gap between nonprofit and for-profit homes under asymmetric information 
becomes more significant and bigger. For example, the differences of having dehydration within 1 and 2 years between nonprofit and for-profit are $12.2 \%$ and $20.3 \%$ lower with asymmetric information than without.

Results on dehydration and urinary tract infections suggest that the effect of nonprofit versus for-profit status on the quality of care is bigger when there is asymmetric information between nursing homes and patients or their family members. When the residents lack family members to monitor the service, the for-profit homes will have less incentive to maintain the quality of care. These empirical results are in favor of the contract failure theory. Although nonprofit homes may be established based on altruistic motivations and may provide better services, the effect of the nonprofit nondistribution constraint will be more manifest when asymmetric information exists.

Finally, I also carry out two specification tests to rigorously check the potential selection problem. The above estimation strategy will be valid only if the differences between nonprofit and for-profit home residents with and without asymmetric information are similar. Otherwise, selection into groups made up of residents is likely to be non-random since it depends intricately on the nature of the asymmetric information. For example, if nonprofit home residents are those who are better able to assess the quality of service because of better mental and physical health conditions which are not captured by the health indicators, this selection process may bias the estimation results.

One way to test the potential sorting effects is to run regressions similar to Eq. (9) for those demographic and health variables. Explanatory variables include two ownership dummies, indicator of asymmetric information and two dummies for interaction between ownership status and asymmetric information. Table 5 shows the estimated coefficients of the interaction between nonprofit status and asymmetric information $\left(\beta_{4}\right)$. There is a significant amount of overlap in the nonprofit and for-profit home residents with and without asymmetric information. White people are more likely to choose nonprofit homes under asymmetric information. If white people are healthier, then I may risk explaining the

Table 5

Difference-in-differences estimates on demographic and health variables

\begin{tabular}{lcc}
\hline & \multicolumn{2}{l}{ Estimated coefficient of $\beta_{4}$} \\
\cline { 2 - 3 } & Coefficient & S.E. \\
\hline Personal characteristics & 0.003 & \\
Male & 0.150 & 0.034 \\
Age (at nursing home admission) & $0.076^{\mathrm{a}}$ & 0.564 \\
White & 0.178 & 0.023 \\
Education (years) & -0.333 & 0.202 \\
Income (in 1994 US\$, '000) & -0.037 & 0.664 \\
Married & & 0.024 \\
Health before entering nursing homes & $-0.212^{\mathrm{b}}$ & \\
No. of ADLs & -0.131 & 0.123 \\
Cognition score & 0.053 & 0.302 \\
Risk score & 0.075 \\
\hline
\end{tabular}

\footnotetext{
${ }^{\text {a }}$ Statistically significant at the $1 \%$ level.

${ }^{\mathrm{b}}$ Statistically significant at the $10 \%$ level.
} 
Table 6

First-stage of multinomial logit for endogeneity tests ${ }^{\mathrm{a}}$

\begin{tabular}{lcc}
\hline & $\begin{array}{l}\text { Government } \times \text { asymmetric } \\
\text { information }\end{array}$ & $\begin{array}{l}\text { Nonprofit } \times \text { asymmetric } \\
\text { information }\end{array}$ \\
\hline Population density & $0.049^{\mathrm{b}}(0.016)$ & $0.044^{\mathrm{b}}(0.010)$ \\
Flat-rate system & $-0.240(0.260)$ & $0.303^{\mathrm{c}}(0.124)$ \\
Medicaid reimbursement rate & $-0.526(0.746)$ & $-0.599^{\mathrm{d}}(0.343)$ \\
No. of nursing home beds/population $>65$ & $9.327(2.743)$ & $-1.532(1.730)$ \\
\hline
\end{tabular}

a S.E. are in parentheses.

${ }^{\mathrm{b}}$ Statistically significant at the $1 \%$ level.

${ }^{\mathrm{c}}$ Statistically significant at the $5 \%$ level.

d Statistically significant at the $10 \%$ level.

preexisting outcomes. Since the differences between white and non-white under asymmetric information in terms of the mean differences of limitations on ADLs, risk scores and cognition scores are not significant (results are not reported), this problem has little effect on the results. The differences in cognition and risk scores are similar with and without asymmetric information. The limitation on ADLs is statistically significant at the $10 \%$ level, which may cause estimation bias. Since the magnitudes of coefficients and marginal effects of ADLs are all relatively small compared with difference-in-differences estimates and insignificant in outcome equations, ${ }^{16}$ the selection process would not cause a serious estimation bias.

To rigorously check the exogeneity of two interaction terms in Eq. (9), Hausman tests are used. In the linear probability model, the chi-square statistics with two degrees of freedom are $0.15,2.11,5.05$ and 3.09 for mortality, decubitus ulcers, dehydration and urinary tract infections, respectively, which are all smaller than the $95 \%$ critical value of $\chi_{(1)}^{2}$ to reject the null hypothesis that the interactions between ownership status and asymmetric information are exogenous. These results further confirm the previous conclusion that the potential sample selection should not cause a serious estimation bias in this study.

The instrumental variables used in the two-stage least square estimation are population density, Medicaid reimbursement type, Medicaid reimbursement rate and number of nursing home beds relative to the population over 65. Results are reported in Table 6. Medicaid reimbursement type and Medicaid reimbursement rate are included based on the idea from Lakdawalla and Philipson (1998) that the share of nonprofit production falls with the availability and the level of public demand subsidies. The empirical results are consistent with the theoretical prediction that the patients are more likely to choose nonprofit homes in a state which has a flat-rate reimbursement system and a low reimbursement rate. Population density and number of nursing home beds relative to the population over 65 are included to capture the market structure. As the number of nursing homes increases (market becomes more competitive), consumer information about each nursing home decreases; thus, potential residents have a more difficult time in the search for a nursing home. Consequently, they may tend to choose nonprofit homes. Another argument is that the nonprofit share of an

\footnotetext{
${ }^{16}$ For example, the coefficients of ADLs are $-0.032,0.142,0.033$ and 0.0063 for mortality, decubitus ulcers, dehydration and urinary tract infections, respectively, which are all smaller in absolute values than the coefficients reported in the first panel of Table $3(-0.261,-0.442,-0.504$, and -0.434$)$.
} 
industry is positively related to the degree of competition (Lakdawalla and Philipson, 1998). The significantly positive effect of population density on nonprofit status under asymmetric information is consistent with both arguments. Result for number of nursing home bed is not statistically significant. Finally, the pseudo $R^{2}$ is 0.066 .

\section{Conclusions}

This article presents the first empirical evidence on how the effects of organizations with different ownership types vary with the presence or non-presence of asymmetric information. The presence of asymmetric information is defined when residents have no spouse and no child visiting within 1 month of admission. Most of the previous empirical studies only examined the difference between nonprofit and for-profit organizations; however, they all ignored the mediating effect of asymmetric information on this difference. The nursing home industry, with mixed organizational forms, provides an invaluable opportunity to examine this issue. The results on two of four quality indicators suggest that the differences between for-profit and nonprofit homes are more manifest when asymmetric information is present. This finding is consistent with the contract failure theory or incomplete contract theory. The nonprofit nondistribution constraint will soften the incentive to exploit those aspects of quality of service which are hard to monitor. On the contrary, for-profit homes are more likely to take advantage of their patients to make a profit. The specification test shows the patients with asymmetric information in nonprofit homes have fewer limitations on ADLs, which may cause a bias in difference-in-differences estimations. Since the impact of ADLs on outcomes is generally small relative to the difference-in-differences estimates, this suggests that the bias from this source is at most minor.

This study not only highlights the importance of asymmetric information, but also presents important policy implications for the design of ownership in the nursing home market. To the extent that some aspects of the service are difficult to assess, intervention through regulation of quality of care may be justified. An alternative policy choice is to design systems whereby institutions can reduce informational costs. For example, the tax advantages granted to the nonprofit firm will be one way to preserve nonprofit homes and reduce monitoring costs.

It is noteworthy, in this regard, that the percentage of for-profit homes has decreased by $23 \%$ between 1985 and 1995, while voluntary nonprofit-operated nursing homes have shown a $13.2 \%$ increase and government-owned nursing home have increased by $40 \%$ during the same period (Strahan, 1997). One potential reason is that investment in nursing home care is not as lucrative as it was in the late 1960s and 1970s. Another possible reason is that some for-profit homes are screened out from the market because of shoddy quality of care.

Finally, comparing this study with other studies on the hospital industry should shed more light on the importance of asymmetric information and the difference between nonprofit and for-profit organizations. Most of the studies on hospital behavior which focus on private nonprofit hospitals in comparison to other ownership forms do not suggest significant differences in terms of quality of care. ${ }^{17}$ One potential reason for the different findings

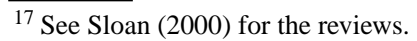


in this study is that for-profit hospitals constitute only a small portion of all hospitals, ${ }^{18}$ suggesting that the problem caused by asymmetric information may be diminished with the dominance of nonprofit hospitals. Furthermore, most acute care patients have family members who can be effective advocates or are able to use the threat of medical malpractice to secure high quality of care.

Moreover, the issue of information asymmetry depends crucially on the role of the physician in the hospital industry. Hospitals are less likely to cheat on quality where the physicians may act as the patient's knowledgeable agent to assess the quality of the hospital service. Unfortunately, many nursing homes are understaffed, and most of the care in nursing homes is provided by aides. Consequently, trained and experienced health care professionals play a much less significant role in the control of nursing home operations than they do in hospitals.

Finally, it might be market competition which leads the nonprofit and for-profit hospitals to converge. However, the certificate-of-need law creates an entry barrier and a less competitive market for the nursing home industry. Under conditions of excess demand with entry barriers, nursing homes can always admit Medicaid patients to fill up the residual beds. Therefore, nursing homes usually have fewer incentives to compete for patients by offering higher quality of care. Obviously, how competition affects the behavior of nonprofit and for-profit homes in the nursing home industry should be an interesting direction for future research.

\section{Acknowledgements}

I would like to thank Frank A. Sloan for many helpful suggestions. I have also benefited from discussions with Edward Norton, Mark An, Holger Sieg, Donald Taylor, Gabriel Picone, Jin-Tan Liu, Li-San Wang and Robert Kaestner. I thank J.S. Butler for making his Fortran program for semiparametric duration model available to me. Jonathan Gruber and one anonymous referee also provide many helpful comments and suggestions. This paper is based on my doctoral dissertation and the research for this study was supported in part by a grant from the National Institute on Aging to Duke University (2RO1-AG-09468-04A1). All errors remain mine.

\section{References}

American Hospital Association, 1998. Annual Statistics. American Hospital Association, Chicago.

Arrow, K.J., 1963. Uncertainty and the welfare economics and medical care. American Economic Review 53, 941-973.

Butler, J.S., Anderson, K.H., Burkhauser, R.V., 1989. Work and health after retirement: a competing risks model with semiparametric unobserved heterogeneity. Review of Economics and Statistics 71, 46-53.

Cohen, J.W., Dubay, L.C., 1990. The effects of Medicaid reimbursement method and ownership on nursing home costs, case mix and staffing. Inquiry 27, 183-200.

Davis, M.A., 1991. On nursing home quality—a review and analysis. Medical Care Review 48, 129-166.

\footnotetext{
${ }^{18}$ In the United States, for-profit hospitals constituted only $15 \%$ of all nonfederal short-term general hospitals in 1996. By contrast, 59\% of hospitals were organized as private non-profits, and the rest were operated by governments (American Hospital Association, 1998).
} 
Davis, M.A., 1993. Nursing home ownership revisited: market, cost and quality relationships. Medical Care 31, 1062-1068.

Dick, A., Garber, A.M., MaCurdy, T.A., 1994. Forecasting nursing home utilization of elderly Americans. In: Wise, D.A. (Ed.), Studies in the Economics of Aging. pp. 365-394.

DxCG, I., 1996, DxCG Software Version: 02e (Medicare) Program Documentation and User's Manual. DxCG Inc., Waltham, MA.

Easley, D., O'Hara, M., 1983. The economic role of the nonprofit firm. Bell Journal of Economics 14, 531-538.

Ellis, R.P., Pope, G.C., Iezzoni, L.I., Ayanian, J.Z., Bates, D.W., Burstin, H., Ash, A.S., 1996. Diagnosis-based risk adjustment for Medicare capitation payments. Health Care Financing Review 17, 101-128.

Garber, A., MaCurdy, T., 1990, Predicting nursing home utilization among the high-risk elderly. In: Wise, D.A. (Ed.), Issues in the Economics of Aging. pp. 173-204.

Gertler, P.J., 1989. Subsidies, quality, and the regulation of nursing homes. Journal of Public Economics 38, 33-52.

Gertler, P.J., 1991. Subsidies, quality, and regulation in the US nursing home industry. In: Paelinck, J.H.P., Duru, G. (Eds.), Econometrics of Health Care. Advanced Studies in Theoretical and Applied Econometrics. Kluwer Academic Publishers, Dordrecht, pp. 117-139.

Glaeser, E.L., Shleifer, A., 2001. Not-for-profit entrepreneurs. Journal of Public Economics 81, 99-115.

Grossman, S.J., Hart, O.D., 1986. The costs and benefits of ownership: a theory of vertical and lateral integration. Journal of Political Economy 94, 691-719.

Hansmann, H.B., 1980. The role of nonprofit enterprise. Yale Law Journal 89, 835-891.

Hart, O., Moore, J., 1990. Property rights and the nature of the firm. Journal of Political Economy 98, 1119-1158.

Hart, O., Shleifer, A., Vishny, R.W., 1997. The proper scope of government: theory and an application to prisons. Quarterly Journal of Economics 112, 1127-1162.

Hawes, C. and C.D. Phillips, 1986. The changing structure of the nursing home industry and the impact of ownership on quality, cost, and access, in: B.H. Gray, ed., For-Profit Enterprise in Health Care (National Academy Press, Washington, DC) 492-541.

Heckman, J., Singer, B., 1984. A method of minimizing the impact of distributional assumptions in econometric models for duration data. Econometrica 52, 271-320.

Hirth, R.A., 1999. Consumer information and competition between nonprofit and for-profit nursing homes. Journal of Health Economics 18, 219-240.

Hoerger, T.J., Picone, G.A., Sloan, F.A., 1996. Public subsidies private provision of care and living arrangements of the elderly. Review of Economics and Statistics 78, 428-440.

Institute of Medicine, 1986. Improving the Quality of Care in Nursing Homes. National Academy Press, Washington, DC.

Lakdawalla, D., Philipson, T., 1998. Nonprofit Production and Competition. NBER Working Paper, No. 6377.

Newhouse, J.P., 1970. Toward a theory of nonprofit institutions: an economic model of a hospital. American Economic Review 60, 64-74.

Nyman, J.A., 1988. Improving the quality of nursing home outcomes-are adequacy or incentive oriented policies more effective? Medical Care 26, 1158-1171.

Rose-Ackerman, S., 1996. Altruism, nonprofits, and economic theory. Journal of Economic Literature 34, 701-728.

Scanlon, W.J., 1980. A theory of the nursing home market. Inquiry 17, 25-41.

Sloan, F.A., 2000. Not-for-profit ownership and hospital behavior. In: Newhouse, J.P., Culyer, A.J. (Eds.), Handbook of Health Economics. North-Holland, Amsterdam.

Spector, W.D., Selden, T.M., Cohen, J.W., 1998. The impact of ownership type on nursing home outcomes. Health Economics 7, 639-653.

Strahan, G.W., 1997. An Overview of Nursing Homes and Their Current Residents: Data from the 1995 National Nursing Home Survey, Advance Data from Vital and Health Statistics 280.

Weisbrod, B.A., Schlesinger, M., 1985. Public, private, nonprofit ownership and the response to asymmetric information: the case of nursing homes. In: Rose-Ackerman, S. (Ed.), The Economics of Nonprofit Institutions-Studies in Structure and Policy. Oxford University Press, New York, Oxford, pp. 133-151.

Zinn, J.S., 1994. Market competition and the quality of nursing home care . Journal of Health Politics, Policy and Law 19, 555-582.

Zinn, J.S., Aaronson, W.E., Rosko, M.D., 1993. Variations in the outcomes of care provided in Pennsylvania nursing homes: facility and environmental correlates. Medical Care 31, 475-487. 